\title{
Educational Approach to Increase Student Pharmacist Confidence with Medicare
}

Adriane N Irwin, MS, PharmD

Oregon State University College of Pharmacy

\begin{abstract}
Objective: To describe a didactic, case-based approach to teach student pharmacists about Medicare enabling them to consider the spectrum of coverage options, as well as both medical and drug needs, when assessing insurance plans.

Innovation: Education on Medicare often focuses on Part D. However, the growing popularity of Medicare Advantage plans requires students to have a more comprehensive understanding of Medicare. To address this gap, a didactic, case-based approach was developed where students received four 90-minute lectures on Medicare and then applied the information through a patient case. Data was collected on student-reported confidence with Medicare, and attitudes towards the importance of understanding insurance in improving patient care. Surveys were conducted at baseline, after the didactic lectures (interim survey), and upon project completion (final survey).

Key Findings: Confidence with Medicare increased between the baseline and interim survey (all $p \leq 0.001$ ). Additional gains were seen after completing the project in helping patients navigate financial assistance programs ( $p \leq 0.001)$ and selecting specific plans ( $p \leq 0.05)$. After the interim survey, students more strongly agreed with statements related to knowledge of insurance as an opportunity to help advocate for patients ( $p \leq 0.001$ ), and the need to consider Medicare coverage when making medication recommendations ( $p \leq 0.05$ ) Conclusion: The combination of didactic lectures and a case-based exercise positively impacted self-reported student confidence in their knowledge, as well as attitude towards Medicare. Increasing student confidence in Medicare and willingness to engage beneficiaries in conversations about insurance coverage may be a strategy to improve patient care and health outcomes.
\end{abstract}

Keywords: attitude of health personnel, insurance, Medicare, patient medication knowledge, pharmacy education, pharmacy students

\section{DESCRIPTION OF THE PROBLEM}

Pharmacists are the most accessible healthcare professionals and have substantial experience with insurance coverage. Accreditation Council for Pharmacy Education's (ACPE) standards also state that students should be able to assist patients and caregivers in obtaining medications in an affordable manner, through both private and public health insurance options, prior to entry into advanced pharmacy practice experiences (APPEs). ${ }^{1}$ As a result, pharmacists and student pharmacists are well positioned to assist patients in navigating enrollment into Medicare, reviewing options based on individual circumstances, and facilitating connections with appropriate resources.

Efforts to teach student pharmacists about Medicare have been described previously. This work has been largely focused on Medicare Part D, specifically standalone Part D plans (PDPs). These efforts have demonstrated that students can attain good knowledge of Part D through didactic lecture, APPE and cocurricular experiences, as well as combination didactic and problem-based learning. ${ }^{2-7}$ A statewide research project involving seven pharmacy schools across California, found that studentdelivered lectures were effective in improving self-assessed Part D knowledge when used to educate patients and healthcare professionals on the Medicare Part $D$ benefit. ${ }^{5}$

Corresponding author: Adriane N Irwin, MS, PharmD, BCACP

Oregon State University College of Pharmacy

203 Pharmacy, Corvallis, OR 97331

P: (541) 737-5722; F: (541) 737-3999;

Email: Adriane.Irwin@oregonstate.edu
However, since implementation of Medicare Part D, which spurred development of the aforementioned educational approaches, the Medicare landscape has dramatically changed. The number of individuals enrolled in Medicare Advantage (MA) plans has grown from 6.8 in 2006 to 22.0 million in 2019, now representing the coverage structure for $34 \%$ of beneficiaries nationwide. ${ }^{8}$ Thus, to fully assist Medicare beneficiaries, students must be able to evaluate drug coverage options within both standalone PDPs and MA plans, as well as assess the subsequent impact of these approaches on a patient's medical coverage. This requires a more comprehensive understanding of Medicare. As a result, the purpose of this paper is to outline a didactic, casebased approach to prepare student pharmacists to consider the spectrum of coverage options, as well as both medical and drug needs, when assessing insurance plans. A secondary purpose is to describe the impact of this approach on student confidence with Medicare and development of attitudes in viewing insurance knowledge as an opportunity for patient advocacy and improved patient care.

\section{THE INNOVATION \\ Design}

Health Systems I is a required 3-credit course for first year professional students at Oregon State University (OSU) College of Pharmacy. It is an examination of the organization, delivery, and financing of the United States healthcare system. Emphasis is given to the changing relationships between patients, providers, and insurers due to market forces, government regulations, and other factors. 
Students receive four 90-minute lectures on Medicare and then complete a case-based project to reinforce the material. The project's underlying premise is that students select the best option(s) for Medicare coverage, using patient specific characteristics, while working with elderly and disabled individuals. The project is submitted as a 10-page paper organized into three sections. In the first section, students outline three strategies for the beneficiary to obtain coverage. The purpose of this section is for students to detail differences in medical and drug insurance coverage, including associated cost sharing, between Original Medicare (i.e., Part A and B) alone, Original Medicare plus a Medigap (without or without a PDP), or a MA plan. Students then select a specific strategy (e.g., Original Medicare + Medigap + PDP) and compare plans offered by private companies within that strategy in the second section. In the final section, students reflect on the process and address whether the patient could have successfully navigated the situation, potential challenges they could have encountered, and the opportunity created by knowledge of Medicare and the health care system to assist this patient.

All papers have the same general framework, but students must tailor their approach based on challenges specific to each case, such as: 1) supplemental coverage selection for patients with different health care needs, 2) application of different enrollment periods (e.g., initial, special, and general enrollment periods), 3) calculation of Part B and D penalties, 4) mechanisms to acquire or change insurance plans midyear, and 5) dual eligibility (i.e., Medicare-Medicaid) (Appendix A). Additionally, while some demographics are provided, students are expected to develop a more robust "backstory," and this added information must align with the selected strategy and plan recommendation(s). Projects take $15-20$ hours to complete.

Five cases are developed each year with students completing one of five cases. Students can opt to complete the first two sections of the paper individually, in pairs, or a group of three (selfselected), but each student is responsible for an individual reflection. Decisions related to the groups for the paper occur prior to cases being released. Once the number of groups is determined, cases are assigned to ensure equal distribution across the class. After writing the full paper, students then engage in a small group discussion with a different group of students. These small groups consist of five students, with one student having completed each case. This discussion is approximately 50 minutes ( 7 minutes per case, plus time for noncase questions), and allows students to be exposed to all cases. Students are given guidance for this discussion, but it is not formally facilitated. Afterwards, the class convenes for a 30minute debrief where the major teaching points from each case are reviewed.

\section{Evaluation}

Student-reported confidence with Medicare and attitudes towards the importance of understanding insurance and the role of the pharmacist was collected with students enrolled in Health Systems I during fall term of 2017. The tool was comprised of eight questions - five questions focused on confidence and three on attitudes - and used five-response options (Table 1). Most questions were taken from a published survey of a Medicare Part D education program for health profession students. ${ }^{5}$ Items were used directly or adapted to replace "Medicare Part D" with "Medicare" to reference the full benefit. Items 2 and 3 in the confidence section were developed by the course instructor, based on lecture learning objectives. The survey was administered by hardcopy on the first day of class (baseline survey), after completion of the didactic lectures during the midterm exam (interim survey), and upon completion of the project and small group discussion (final survey). Completion of all surveys was voluntary.

Data were analyzed with descriptive and inferential statistics. Categorical data is described using number (percentage) or median (interquartile range [IQR]). Differences between timepoints were assessed using a Kruskal-Wallis test. Post-hoc pairwise comparisons were assessed using the Dunn test adjusted for multiple comparisons using the Bonferroni methods. Statistical significance was set at a $p$-value of $<0.05$. Cronbach's alpha was calculated to determine the internal reliability of questions within the confidence and attitude domains. Data analysis was conducted using $\mathrm{R}$, an opensource environment for statistical computing, with the exception of Cronbach's alpha's which were calculated using Microsoft Excel V16 (Redmond, WA). All study activities were reviewed and approved by the Oregon State University Institutional Review Board. 
Table 1. Student Reported Confidence in Understanding of and Attitudes toward Medicare (median, interquartile range [IQR])

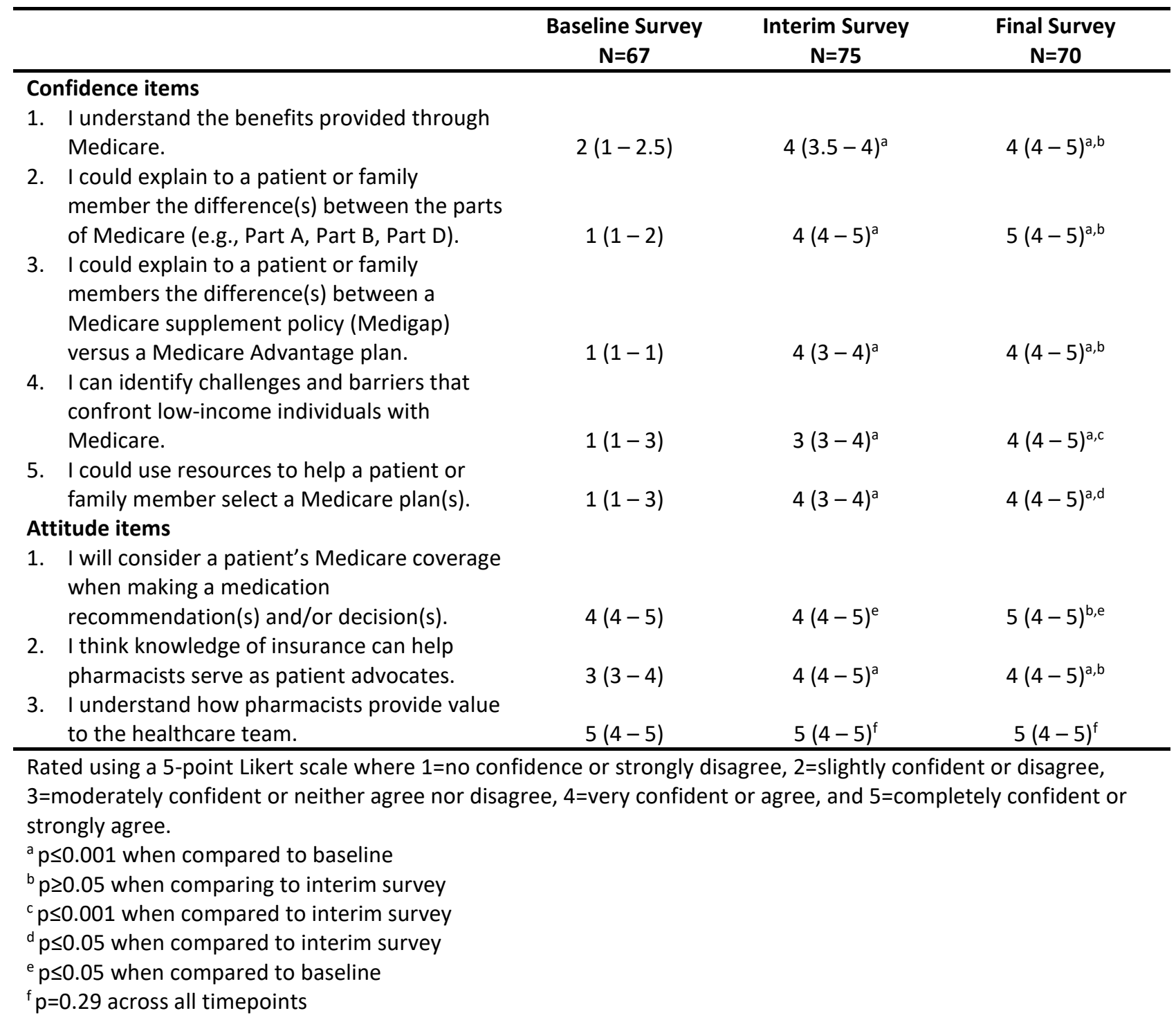

\section{Findings}

A total of 91 students were enrolled in the course. A total of 67 respondents $(73.6 \%)$ completed the baseline survey, while 75 $(82.4 \%)$ and $70(76.9 \%)$ students completed the interim and final surveys, respectively. Respondents were $25.2 \pm 4.6$ year of age and evenly divided between males and females. The majority had previous pharmacy experience through either a paid $(n=36$; $53.7 \%)$ or volunteer $(n=16 ; 23.9 \%)$ position, but fewer reported receiving exposure to Medicare through work experiences $(n=19$; $28.4 \%)$.

Respondents reported limited understanding of the Medicare benefit (median $=2 ; I Q R=1-3$ ) at baseline (Table 1 ). They reported even less understanding of the different Medicare parts, differences between Medigap verses MA plans, assistance available for low-income beneficiaries, and resources available to assist beneficiaries in plan selection(s) (all median $=1$ ).
Respondent-reported confidence with Medicare increased on all questions between the baseline and interim survey (all $p \leq 0.001$ ). Additional confidence was seen with navigating low-income assistance programs at the final survey $(p \leq 0.001)$, and helping others select a specific plan(s) ( $p \leq 0.05)$. For the set of items focused on confidence, Cronbach alpha was 0.922 at baseline, 0.801 at the interim, and 0.850 at the final survey.

At the interim survey, as compared to baseline, respondents more strongly agreed with statements about viewing knowledge of insurance as a strategy to help advocate for patients ( $p \leq$ 0.001 ), and the need to consider Medicare coverage when making medication recommendations $(p \leq 0.05)$. No changes were seen in the item related to pharmacists provided value to the healthcare team ( $p=0.29$ across all time points). For the set of items focused on attitudes, Cronbach alpha was 0.591 at baseline, 0.695 at the interim, and 0.779 at the final survey. 


\section{CRITICAL ANALYSIS}

Strategies to improve student pharmacist understanding of the Medicare Part D drug benefit have been documented, but changes to the Medicare landscape require pharmacists to have an even broader understanding of Medicare, when assisting beneficiaries in making enrollment decisions. This report provides a more comprehensive approach, with the focus being on the differences between enrolling in a Medigap plan plus standalone PDP versus a MA plan with drug coverage. It also exposes students to a range of more complex topics. Results suggest that this didactic case-based exercise positively impacted student-reported confidence in knowledge of and attitudes towards Medicare.

Research demonstrates that Medicare beneficiaries do not fully understand the different aspects of Medicare, how to compare plans, and make decisions based on individual circumstances. ${ }^{9}$ As a result, the lack of strategies to teach the full Medicare benefit is somewhat surprising given the increasing prevalence of MA plans. However, the lack of attention to MA plans, or the differences between Medigap versus MA plans, may reflect the overall unfamiliarity of the information by practicing pharmacists and pharmacy faculty. The cases in this exercise were developed by a faculty member who is trained by the Oregon Senior Health Insurance Benefits Assistance program and regularly provides Medicare counseling within an ambulatory care practice site. ${ }^{10}$ Cases were adapted from actual experiences to increase the relevancy of the scenarios. However, other schools and colleges of pharmacy may not have faculty with comparable Medicare experience.

The insignificant growth in student confidence between the interim and final survey was initially surprising. However, in the self-reflection component, students often discussed that preparing for the midterm exam was easier than applying information to an actual situation, and that the case highlighted individual knowledge gaps and nuances within Medicare. As result, student-reported confidence at the interim survey may reflect an overestimation of abilities. This would be consistent with other educational strategies, which documented students taking more time to complete a Medicare Plan Finder Tool exercise after participating in outreach events as compared to the classroom component. ${ }^{3}$ The authors speculated that students became increasingly aware, diligent, and critical in evaluating situations.

\section{NEXT STEPS}

While student-reported confidence is a valuable measure, complementing this work with objective measures (i.e., exam scores) would provide a more accurate assessment of knowledge at the different timepoints. This was not collected as part of this initial investigation due to challenges with university policies related to the use of graded activities for research purposes. Similarly, assessing any impact on knowledge retention may be appropriate as this approach addresses a higher level of learning as compared to lecture alone.
Additionally, students are participating in Medicare counseling through elective courses and co-curricular activities. ${ }^{3,4}$ However, one of the barriers cited to expanding these opportunities to all students was manpower, specifically a lack of pharmacist preceptors. ${ }^{4}$ Medicare counseling could be a natural complement to current co-curricular offerings, and it would help students develop skills aimed to help them address medication access issues for patients. However, scaling these activities would require infrastructure development and preceptor training programs.

\section{SUMMARY}

A didactic case-based approach may be a strategy to educate student pharmacists on the full Medicare benefit and introduce more complex scenarios involving Medicare coverage. This approach resulted in a positive impact on student-reported confidence in knowledge of and attitudes toward Medicare, although more research is needed to quantify objective knowledge gains. Increasing student confidence in Medicare and willingness to engage beneficiaries in conversations about insurance coverage may be a strategy to improve patient care and health outcomes.

\section{Funding/Support: None \\ Conflict of Interest: None}

Acknowledgements: I would like to thank Brie Noble, Senior Faculty Research Assistant, Oregon State University College of Pharmacy, for assistance with the statistical analysis.

\section{REFERENCES}

1. Accreditation Council for Pharmacy Education. . Guidance for the Accreditation Standards and Key Elements for the Professional Program in Pharmacy Leading to the Doctor of Pharmacy Degree. (Guidance for Standards 2016). Published February 2015. https://www.acpeaccredit.org/pdf/GuidanceforStandards2016FINAL.pdf. Accessed January 2, 2021.

2. Cutler TW, Stebbins MR, Lai E, Smith AR, Lipton HL. Problem-based learning using the online Medicare Part D Plan Finder tool. Am J Pharm Educ. 2008;72:47. doi: 10.5688/aj720347

3. Galal SM, Patel RA, Thai HK et al. Impact of an elective course on pharmacy students' attitudes, beliefs, and competency regarding Medicare Part D. Am J Pharm Educ. 2012;76:91. doi: 10.5688/ajpe76591

4. Stebbins MR, Cutler TW, Corelli RL, Smith AR, Lipton HL. Medicare Part D community outreach train-the-trainer program for pharmacy faculty. Am J Pharm Educ. 2009;73:53. doi: 10.5688/aj730353 
5. Lai CJ, Smith AR, Stebbins MR, Cutler TW, Lipton HL. Promoting interprofessional collaboration: pharmacy students teaching current and future prescribers about Medicare Part D. J Manag Care Pharm. 2011;17:43948. doi: 10.18553/jmcp.2011.17.6.439

6. Lipton HL, Lai CJ, Cutler TW et al. Peer-to-peer interprofessional health policy education of Medicare Part D. Am J Pharm Educ. 2010:74:102. doi:10.5688/aj7406102

7. Urmie JM, Farris KB, Herbert KE. Pharmacy students' knowledge of the Medicare drug benefit and intention to provide Medicare medication therapy management services. Am J Pharm Educ. 2007;71:41. doi: 10.5688/aj71034

8. Medicare Advantage. Menlo Park, CA: The Henry J Kaiser Family Foundation; June 6, 2019. https://www.kff.org/medicare/fact-sheet/medicareadvantage/. Accessed January 2, 2021.

9. Jacobson G, Swoope C, Perry M, Slosar MC. How are seniors choosing and changing health insurance plans? Menlo Park, CA: The Henry J Kaiser Family Foundation; May 2014. https://www.kff.org/wpcontent/uploads/2014/05/8589-how-are-seniorschoosing-and-changing-health-insurance-plans.pdf. Accessed January 2, 2021.

10. Irwin AN, Manning EHM. Implementation of a pharmacist-delivered Medicare counseling service in a rural community health center. J Am Pharm Assoc. 2020:60:e79-e85. doi: 10.1016/j.japh.2020.02.008 
Appendix A. Sample patient cases

\section{Patient Case 1:}

DC is a 69-year old female who presents to the pharmacy to fill a prescription for azithromycin. You notice that the prescription was written by a physician at the local emergency department and the patient has not provided any insurance information. As a result, you decide to investigate the situation further.

She states that she legally moved to the United States 7 years ago from Mexico to live with her son following the death of her husband. She states that she tried to apply for Medicare but was informed that she was not eligible because she did not have any work history in the United States.

Monthly Income: $\$ 778$, She states that she makes a little money by working part-time as a housekeeper, but otherwise, she is financially dependent on her son and his family.

Zip Code: 97330

Health Provider Utilization: Other than her recent emergency department visit, DC states that she is generally healthy. She visits her doctor once annually to refill her medications.

\section{Medication List:}

aspirin $81 \mathrm{mg} 1$ tablet daily

glyburide $5 \mathrm{mg} 1$ tablet twice daily

metformin $1000 \mathrm{mg} 1$ tablet twice daily

lisinopril $20 \mathrm{mg} 1$ tablet daily

pravastatin $40 \mathrm{mg} 1$ tablet daily

Select Learning Points:

This case highlights points related to Medicare eligibility, enrollment periods, and assistance programs for beneficiaries with limited income.

- Eligibility: While most individuals become Medicare eligible when they turn age 65 , students should recognize other eligibility criteria. Specifically, lawfully admitted aliens who have constantly lived in the United States become eligible for Medicare after 5 years, or at age 67 in this case. This individual has not paid Medicare taxes for 40 quarters and thus does not qualify for premium free Part A; however, this would not impact her eligibility. Students should identify the incorrect information presented above.

- Enrollment Periods: This individual should have enrolled in Medicare through her initial enrollment period (IEP), which occurred after 5 years of residence in the United States. Students should identify that this individual missed her IEP, and as a result, she would likely need to enroll through the general enrollment period (GEP).

- Assistance Programs: Students should recognize that the monthly income provided would qualify this patient for a Medicare Savings Program (MSP) and Low-Income Subsidy (LIS) to help with medical and drug expenses, respectively. Students should recognize that this patient is a Qualified Medicare Beneficiary (QMB) and describe that QMB provides assistance for this patient's Part A and B monthly premiums as well as any deductibles, coinsurances, and copayments. Student should recognize that LIS will reduce prescription copayments and fully cover or reduce a drug plan's monthly premium. Fully complete answers also address that MSP/LIS eligibility provides this individual with continuous enrollment verses waiting for the GEP, and it would pay any penalties secondary to late enrollment.

\section{Patient Case 2:}

$\mathrm{JV}$ is a 64-year-old female who will be turning 65 in 2 months. She is currently employed and covered by an employer group health plan. However, she is planning to retire once she is Medicare eligible due to recent health issues. She recently underwent a mastectomy and completed chemotherapy with trastuzumab and paclitaxel for breast cancer. As a result, she was interacting regularly with the healthcare system. However, her cancer is now in remission and the number of interactions has decreased. She is planning to have a breast reconstruction in about 6 months. She wants to ensure that she is covered for this procedure as well as any future needs if the cancer were to return. 
Monthly Income: $\$ 1,643$ (expected upon retirement). She also states that she has a "good nest egg" to help with expenses in retirement.

Zip Code: 97456

Health Provider Utilization: See above

\section{Medication List:}

hydrochlorothiazide/lisinopril 25/20 mg 1 tablet daily

tamoxifen $20 \mathrm{mg} 1$ tablet daily

\section{Select Learning Points:}

This case highlights points related to enrollment periods and the decision whether to enroll in a Medigap and standalone Part $D$ plan or a Medicare Advantage plan with drug coverage.

- Enrollment Periods: Students should identify that this individual will be enrolling in Medicare through her initial enrollment period and provide the associated details.

- Medigap versus Medicare Advantage: Students should outline coverage provided by Original Medicare (i.e., Part A and Part B), including cost sharing, to illustrate why supplemental coverage is essential in this case. Students should discuss the differences in obtaining supplemental coverage through a Medigap versus a Medicare Advantage plan. Information in lecture would encourage selection of a Medigap plan due to the anticipated medical expenses and patient-reported desire to minimize financial risk related to healthcare expenses.

- Assistance Programs: Fully complete answers would address potential eligibility for a Low-Income Subsidy (LIS) to assist with drug expenses. If she was married, then her income would be below the income threshold. However, students should identify that she would likely be ineligible due to her resources. 